\title{
Crustal complexity from regional waveform tomography: Aftershocks of the 1992 Landers earthquake, California
}

\author{
D. V. Helmberger, X. J. Song, ${ }^{1}$ and L. Zhu \\ Seismological Laboratory, California Institute of Technology, Pasadena
}

\begin{abstract}
We construct a two-dimensional velocity section sampling the Mojave crustal block in southern California by modeling shear wave $(\mathrm{SH})$ seismograms. Our approach uses individual generalized rays computed from a layered model. The model is divided into blocks with variable velocity perturbations such that ray responses are allowed to shift relative to each other to maximize synthetic waveform fits to data. An efficient simulated annealing algorithm is employed in this search. The technique is applied to a collection of 25 aftershocks (Landers earthquake) as recorded at two stations, GSC and PFO, separated by $\sim 200 \mathrm{~km}$, which bracket the event population along the Landers fault system. The events are assumed to have known mechanisms and epicenters, but both their depths and origin times are allowed to vary. The results indicate considerable variation, especially in the top layer (up to $\pm 13 \%$ ), which mirrors surface geology. Best fitting models contain a low-velocity zone in the lower crust if we constrain the crustal thickness $(29 \mathrm{~km})$ from receiver function analysis. Reduced lower crustal velocities imply crustal weakening, which appears compatible with the shallow seismogenic zone found in the northern end of this section. There is also evidence for a lateral jump in velocity of several percent across the San Andreas with the faster velocities on the west.
\end{abstract}

\section{Introduction}

A large number of regional earthquakes have been recorded on broadband instruments with the implementation of modern equipment, especially in southern California. These data contain an immense amount of information about source processes and crustal structure, but it has proved difficult to unscramble these features. Most efforts to date have concentrated on the recovery of source parameters, whereas studies aimed at resolving crustal structure traditionally employ controlled sources. Such studies have many advantages over those using earthquakes as sources in that the origin time and location are fixed and an array of stations can be situated to maximize path sampling. Waveform modeling has been used to improve models based on travel times by applying forward modeling, essentially trial and error perturbations. Uniqueness and resolution are largely based on qualitative arguments with few attempts to quantify measures of fit. Some attempts have been made using the formalism introduced by Backus and Gilbert [1967] where the nonlinear problem of matching waveforms is achieved by constructing derivatives from a nearby starting model [Mellman, 1980; Chapman and Orcutt, 1980]. This technique proves successful at long periods but requires good starting models at the short periods discussed in this paper because the nonlinear behavior of the inversion only allows local minima to be reached. The objective of this paper is to develop a new method that is more robust by applying a simulating annealing algorithm [Song and Helmberger, 1998]. We generate a large number of approximate synthetics by allowing various phases, $S, S_{m} S, s S_{m} S$, etc., to shift relative to one an-

${ }^{1}$ Now at Software Technologies Corporation, Monrovia, CA 91016.

Copyright 2001 by the American Geophysical Union.

Paper number 2000JB900231.

0148-0227/01/2000JB900231\$09.00 other and choosing those that are compatible with tomographic block-like models.

In section 2, we introduce the $S H$ seismograms used in the modeling along with a review of previous studies used to constrain the sources and crustal thickness in this region. Sections 3 and 4 are on our new method and the resulting velocity structure for the Mojave crustal block. Section 5 addresses some issues of increasing further resolution by adding more model constraints provided by receiver function analysis and speculation on possible joint inversions.

\section{Data and Study Area}

The aftershocks used in this study are taken from a subset of those analyzed by Jones and Helmberger [1998]. They applied a grid search procedure called the cut and paste method to determine the source parameters of the larger Landers aftershocks. The method matched the whole three-component seismograms with synthetics by splitting the $P_{n l}$ (extended $P$ wave) from the stronger surface waves and fitting segments individually. Depth estimates were controlled by the interference of $P_{n}, p P_{n}$, and $s P_{n}$ in combination with the strength of $P_{n l}$ to Rayleigh wave [Zhao and Helmberger, 1994; Zhu and Helmberger, 1996]. Thus it is model-dependent. The Landers aftershocks are mostly strike-slip with their mechanisms and depth estimates given in Table 1. These solutions are in general agreement with those of Hauksson et al. [1993] except for some differences in depth estimates, mostly $<3 \mathrm{~km}$ [see Jones and Helmberger, 1998]. Their locations relative to two TERRAscope stations bracketing this region are displayed in Figure 1. A sample of the waveform fits (tangential component) for some of these events at PFO and GSC is displayed in Figure 2. The two deep events, 24 and 31 , can be identified by the lack of significant surface waves. Other source features are the lowest stress drop event (19) and the highest (24), as is apparent from their source durations (Table 1). Note that these source parameters were determined by the full TERRAscope ar- 
Table 1. Event Source Parameters

\begin{tabular}{|c|c|c|c|c|c|c|c|c|c|}
\hline Event & Date & Time, UT & $\begin{array}{c}\text { Depth, } \\
\text { km }\end{array}$ & $\begin{array}{l}\text { Strike, } \\
\text { deg }\end{array}$ & $\begin{array}{l}\text { Dip, } \\
\text { deg }\end{array}$ & $\begin{array}{l}\text { Rake, } \\
\text { deg }\end{array}$ & $\begin{array}{l}\mathrm{T} / 2, \\
\mathrm{~s}\end{array}$ & $\begin{array}{l}\text { Moment, } \\
\text { dyn cm }\end{array}$ & $M_{w}$ \\
\hline 5 & July 5, 1992 & $1055: 43$ & 8 & 331 & 80 & 169 & 0.30 & $5.6 \times 10^{22}$ & 4.5 \\
\hline 6 & July 5, 1992 & $2118: 27$ & 8 & 344 & 70 & 142 & 0.75 & $1.3 \times 10^{24}$ & 5.4 \\
\hline 7 & July 5,1992 & $2233: 46$ & 8 & 336 & 64 & 140 & 0.35 & $4.0 \times 10^{22}$ & 4.4 \\
\hline 8 & July 6, 1992 & $1200: 59$ & 8 & 330 & 76 & 182 & 0.30 & $2.0 \times 10^{22}$ & 4.2 \\
\hline 9 & July 8, 1992 & 0223:11 & 8 & 162 & 66 & 156 & 0.25 & $7.9 \times 10^{22}$ & 4.6 \\
\hline 13 & July 20,1992 & 0408:23 & 8 & 320 & 84 & 224 & 0.30 & $7.1 \times 10^{21}$ & 3.9 \\
\hline 14 & July 20,1992 & 0448:01 & 7 & 358 & 82 & 204 & 0.40 & $4.0 \times 10^{22}$ & 4.4 \\
\hline 15 & July 20,1992 & $1313: 19$ & 5 & 348 & 71 & 183 & 0.30 & $5.6 \times 10^{22}$ & 4.5 \\
\hline 16 & July 24,1992 & $0723: 56$ & 11 & 344 & 60 & 260 & 0.15 & $5.0 \times 10^{21}$ & 3.8 \\
\hline 17 & July 24,1992 & $1814: 36$ & 8 & 351 & 80 & 173 & 0.45 & $2.2 \times 10^{23}$ & 4.9 \\
\hline 18 & July 25,1992 & 0431:59 & 8 & 2 & 76 & 238 & 0.50 & $1.1 \times 10^{23}$ & 4.7 \\
\hline 19 & July 28,1992 & $1827: 03$ & 5 & 310 & 40 & 100 & 0.50 & $1.1 \times 10^{23}$ & 4.7 \\
\hline 20 & Aug. 5, 1992 & $2222: 40$ & 6 & 146 & 82 & 210 & 0.30 & $7.9 \times 10^{22}$ & 4.6 \\
\hline 21 & Aug. 8, 1992 & $1537: 43$ & 8 & 168 & 64 & 164 & 0.20 & $2.0 \times 10^{22}$ & 4.3 \\
\hline 22 & Aug. 11, 1992 & $0611: 17$ & 8 & 336 & 80 & 170 & 0.15 & $1.4 \times 10^{22}$ & 4.1 \\
\hline 23 & Aug. 15, 1992 & $0824: 14$ & 6 & 338 & 58 & 190 & 0.15 & $5,6 \times 10^{22}$ & 4.5 \\
\hline 24 & Aug. 31, 1992 & $0925: 40$ & 12 & 154 & 90 & 160 & 0.15 & $2.0 \times 10^{22}$ & 4.2 \\
\hline 25 & Sept. 9, 1992 & $1250: 45$ & 8 & 112 & 62 & 110 & 0.25 & $20 \times 10^{22}$ & 4.2 \\
\hline 26 & Sept. 15, 1992 & $0847: 11$ & 8 & 156 & 76 & 188 & 0.55 & $6.3 \times 10^{23}$ & 5.2 \\
\hline 27 & Oct. 2,1992 & 0719:57 & 5 & 189 & 83 & 313 & 0.25 & $7.9 \times 10^{22}$ & 4.6 \\
\hline 28 & Oct. 11, 1992 & 1238:12 & 8 & 170 & 64 & 140 & 0.30 & $4.0 \times 10^{22}$ & 4.4 \\
\hline 29 & Aug. 21, 1993 & $0146: 38$ & 9 & 208 & 54 & 278 & 0.30 & $5.6 \times 10^{22}$ & 4.5 \\
\hline 30 & June 16,1994 & $1624: 27$ & 5 & 148 & 61 & 193 & 0.50 & $1.1 \times 10^{23}$ & 4.7 \\
\hline 31 & Aug. 1, 1994 & $2134: 31$ & 14 & 0 & 78 & 202 & 0.20 & $4.0 \times 10^{22}$ & 4.4 \\
\hline 32 & Aug. 7, 1994 & $1510: 25$ & 8 & 352 & 64 & 184 & 0.28 & $3.5 \times 10^{21}$ & 3.7 \\
\hline
\end{tabular}

ray; see Jones and Helmberger [1998] for details. These synthetics were generated from the Jones model, displayed in Figure 3 , and contain the various mechanisms and appropriate depths. Many of the fits are relatively good with noticeable $S_{m} S$ and $s S_{m} S$ phases. Station PFO has a particularly strong $s S_{m} S$ relative to $S$ (first arrival) for events 9 and 7 , while $s S_{m} S$ at station GSC is not so obvious. This same feature was observed by Mori and Helmberger [1996] at short periods. These synthetics show a particularly strong $S_{m} S$ near $92 \mathrm{~km}$, where it reaches critical angle in the Jones model. However, the data have a relatively stronger $S_{m} S$ relative to $S$, higher $\left(S_{m} S / S\right)$ ratio than the synthetics. This feature is in agreement with short period ratios discussed by Mori and Helmberger [1996]. Essentially, this ratio increases rapidly near this range indicative of a shadow zone boundary possibly caused by a low-velocity zone (LVZ) in the lower crust. Such a situation was considered by Ammon and Zandt [1993] in their receiver function analysis of the Landers' broadband station. This station is situated near the center of the profile, as displayed in Figure 1.

Since a trade-off can occur between the differential travel times of $S_{m} S$ relative to $S$ involving the crustal thickness and LVZs, it is essential to independently fix the crustal depth. Receiver function analysis can be used for this purpose as argued by Zhu and Kanamori [2000], who have mapped the crustal thickness in southern California. However, there are still some trade-offs in thickness depending on the number of layers allowed and assumptions about LVZs. Thus we have inverted the GSC receiver functions in this study with results displayed in Figure 3, two-layered model (REC1) and a 21 layered model (REC2). The latter model shows some resemblance to the Landers receiver results [Ammon and Zandt, 1993]. We will show synthetics for these models later. First, we will address the issue of modeling regional records of the type displayed in Figure 2. Developing such a technique is the main objective of this paper where we will assume the sources are known and search for a (two-dimensional) model compatible with observations at GSC and PFO.

\section{Method}

In recent years, there has been widespread use of synthetic seismograms to help constrain velocity models such as in the development of the Jones model displayed in Figure 3. These models are produced by trial and error perturbations generally referred to as forward modeling. Our waveform modeling approach has been introduced earlier by Song and Helmberger [1998] with respect to generating pseudo-Green's functions based on "master events." From generalized ray theory [Helmberger and Engen, 1980], a synthetic seismogram consists of a series of ray responses, $R_{I}(t)$, that describe energy packets arriving at the receiver along various paths as displayed in Figure 4 . These synthetics, $S(t)$, were constructed by summing over ray paths $(n)$ :

$$
S(t)=\sum_{i=1}^{n} R_{i}(t) * f(t)
$$

where $f(t)$ contains the source information. The timing of each individual ray with $m$ segments is determined by

$$
t_{t}=p r+\sum_{j=1}^{m} \eta_{j} d_{j}
$$

where $r$ is the source-receiver separation, $\eta$ is the vertical slowness, $d_{j}$ is the layer thickness, and $p$ is the ray parameter. The number of required rays is determined by comparing the generalized ray synthetic against the reflectivity method [see Song and Helmberger, 1998]. To the first order, the individual ray response $R_{1}(t)$ can be considered a constant and a new synthetic, $R_{i}^{\prime}(t)$, for a neighboring model generated by correcting for the timing shift,

$$
R_{i}^{1}(t)=R_{i}(t+\Delta t) \text { where } \Delta t=\sum_{j} l_{j} d s,
$$




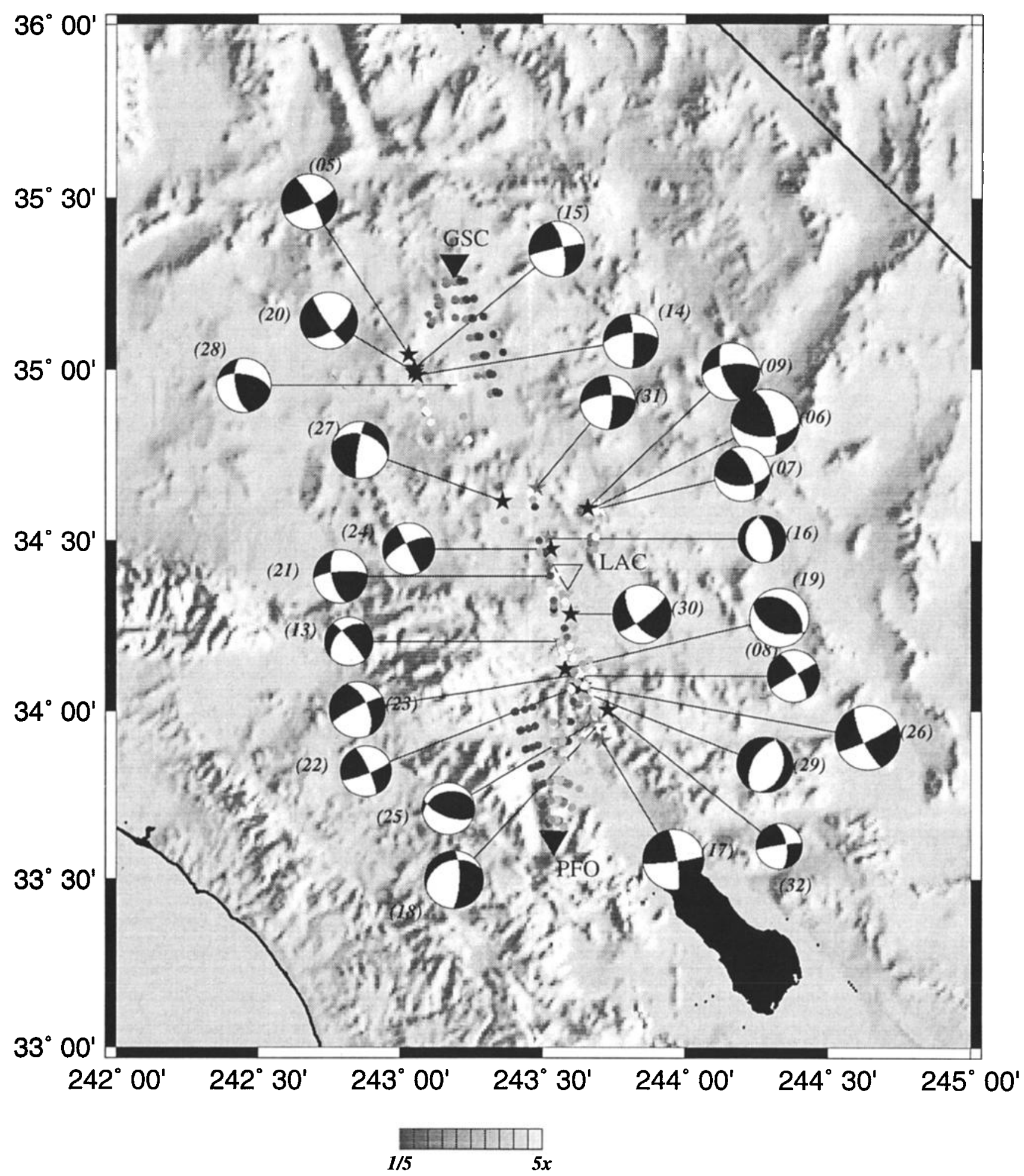

Figure 1. Topographic map of southern California showing Landers aftershocks as black, white, and gray stars. The source mechanisms are after Jones and Helmberger [1998]. The size of the focal spheres is proportional to the event magnitude. Two stations, GSC and PFO, are shown as dark triangles. The small dots indicate surface reflection points of ray paths for $s S_{m} S$ phases (near events) and surface multiples of upgoing $S$ (near stations). The darkness of these dots indicates phase strength relative to a 1-D reference model. 


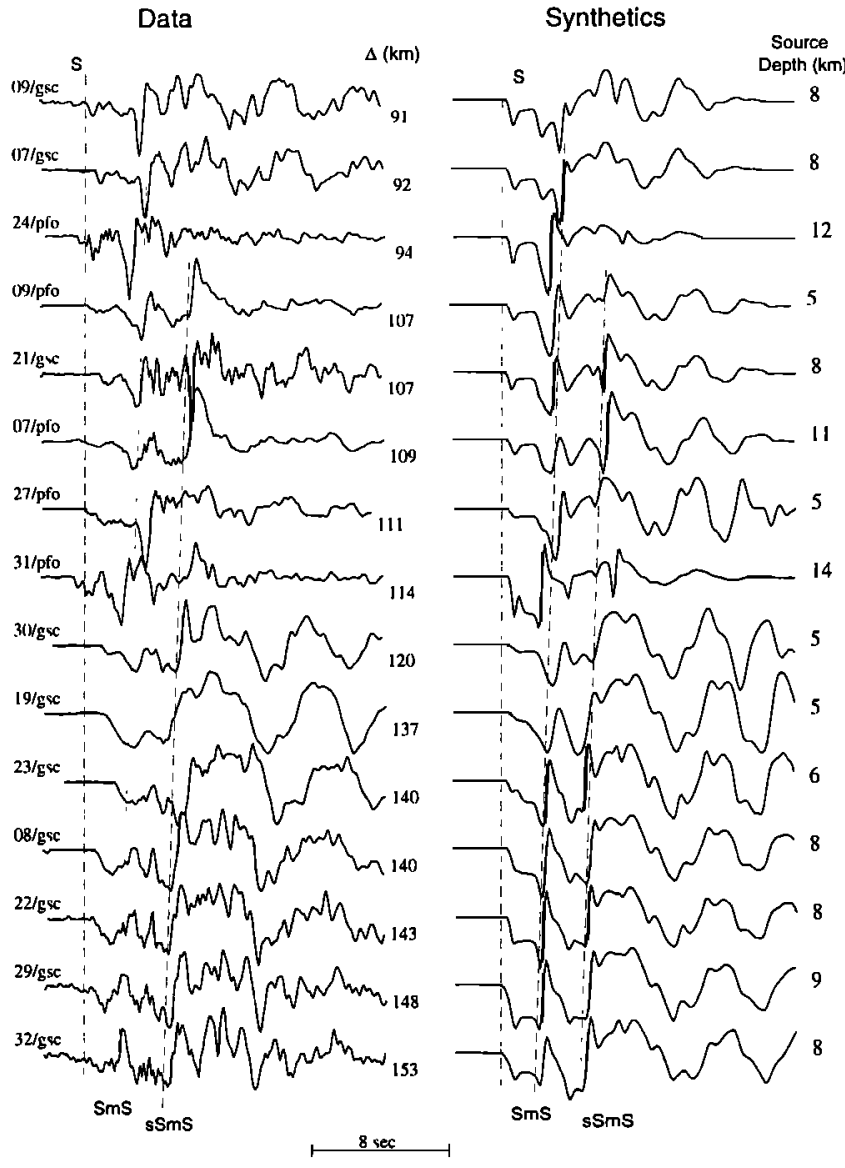

Figure 2. Comparison of (left) observations with (right) synthetics predicted from source estimation [Jones and Helmberger, 1998]. Traces have been plotted on a reduced velocity section $(t-\Delta / 3.6)$. Note that deep events arrive early (event 31 at PFO) and shallow events arrive late (event 9 at PFO). The range estimates and depths have been included in the middle and on the right. Note also that some events appear to be misaligned caused by origin-time problems, i.e., event 23 . The dashed reference lines have been added to indicate the main arrivals, but since the depths are not uniform, we can expect significant shifts. Note the relatively large delay of $s S_{m} S$ for event 31 (depth of $14 \mathrm{~km}$ ).

The shift $\Delta t$ is determined by tomographic approximation, with the velocity perturbation, $d s_{j}$, and the path length, $l_{j}$, in each block $j$. This approximation can be used to generate synthetics for finite faults [Song and Helmberger, 1996] and is a common assumption used in tomographic approaches. If we allow each ray response to shift in time and to vary in amplitude, synthetic fits to data can be dramatically improved. The more freedom we allow in the process, the better the synthetic fits to data [Song and Helmberger, 1998]. Our approach is to parameterize the problem so that the travel time of each ray response is associated with a block velocity model. The travel time of an individual ray is controlled by the integral slowness along its path expression (2), which allows relatively coarse model parameterization. The amplitudes of the ray responses, however, are more sensitive to the velocity perturbation and usually depend on very local changes in the velocity model. Changing the amplitude of individual rays, compared to changing their travel time, proves relatively harder to achieve with only a few blocks in the velocity model. Thus we will usually fix the amplitude of each ray response based on the 1-D model and focus on the timing effect of the model parameterization, as described above.

Our modeling involves multiple parameters. Event depth, origin time, and model velocity along an individual ray path all contribute to the timing of the ray response. With each set of parameters, individual ray responses are shifted differently in time, with their interference constructing a different synthetic seismogram. The problem is defined in terms of obtaining an optimal set of parameters that minimizes the least squares error between data and synthetics. The search is conducted with a simulated annealing algorithm, as discussed in several recent seismological studies [e.g., Sen and Stoffa, 1991; Zhao and Frohlich, 1996]. Figure 5 shows one such example. The reconstruction involves shifting back all the surface wave forming rays, a fraction of a second for the first ray, and gradually increasing to over a second for the last ray. The three rays forming $S_{m} S$ are shifted differentially, with the middle trace moving back slightly. These small adjustments produce a relatively good match of synthetic to observed waveform, although the ratio of $S$ to $S_{m} S$ is too large in the synthetic relative to the observed. The latter feature is difficult to correct without attenuating $S$ or introducing more complex structure along the path.

Since surface multiples can easily overwhelm $S_{m} S$ and $s S_{m} S$, we damp the penalty of misfit with time, thus emphasizing the fit over the time interval particular to the downgoing rays. To do this, we applied to both the data and the synthetics a damping factor $f(t)$, defined as a function of time, $t$, where $x=\left(t-t_{0}\right)$ $/\left(t_{1}-t_{0}\right)$

$$
f(t)=\begin{array}{ll}
1 & t<t_{o} \\
e^{-x} & t<t_{o}
\end{array}
$$

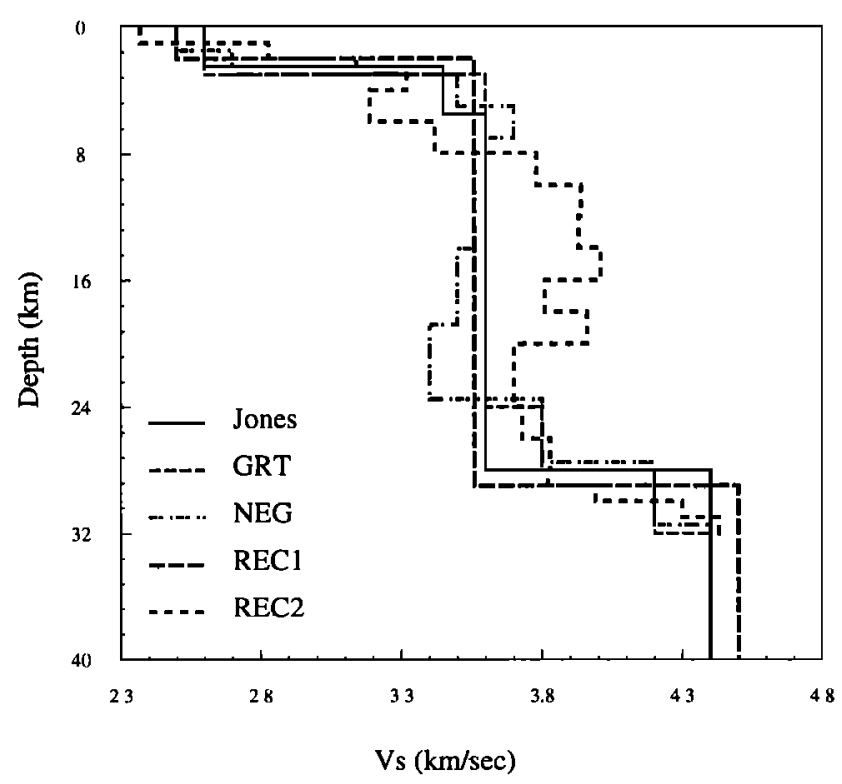

Figure 3. The Jones model is taken from Jones and Helmberger [1998]. The GRT model is the 1-D reference model used in generating the individual ray responses. The NEG model is a 1-D model containing some low-velocity deep structure. The REC1 and REC2 models were produced by a receiver function analyses containing 2 and 21 layers, respectively. 


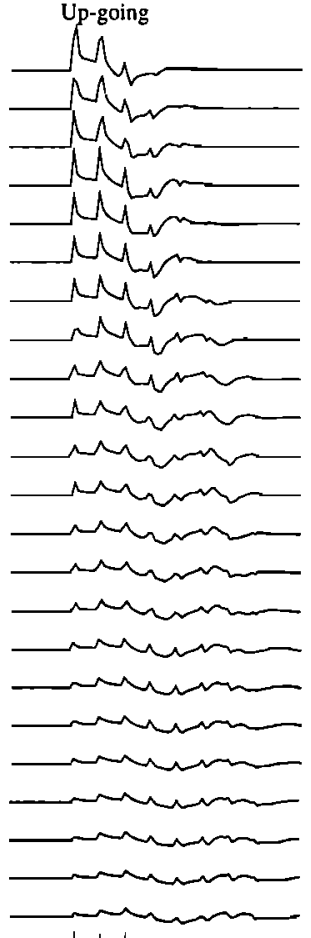

's, s's, sss.

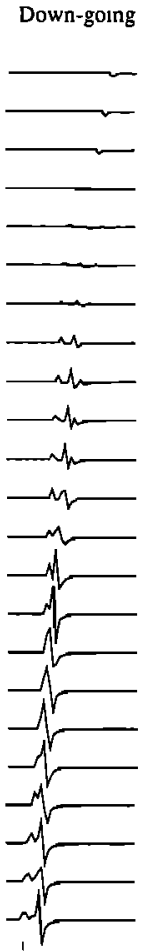

SuS, SmS, S.S

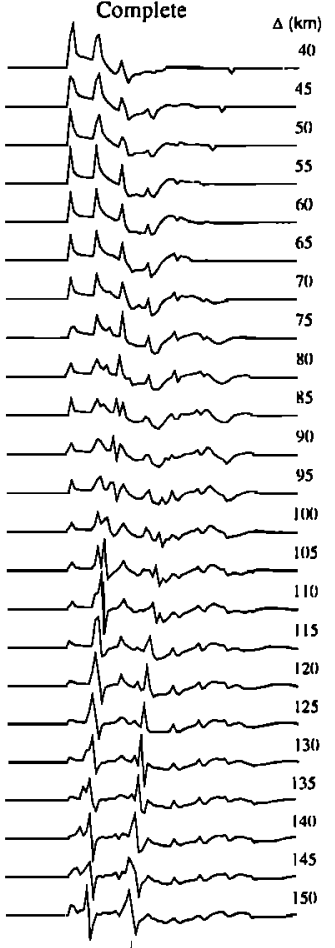

sSuS, sSuS, ss.s

(a)

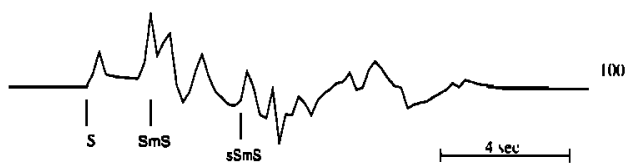

(b)

Figure 4. (a) Columns of synthetics (strike-slip) produced by generalized rays [Helmberger et al., 1983], with upgoing surface wave rays on the left, downgoing $\left(S_{m} S\right)$ in the middle, and complete waveforms on the right. The ranges are noted on the right in $\mathrm{km}$. (b) Synthetic at $100 \mathrm{~km}$ with labels of important arrivals. The model is given in Figure 3 (GRT) where the crustmantle transition consists of two layers, allowing for some flexibility in characterization.

Time constants $t_{0}$ and $t_{1}$ are marked with vertical bars in Figure 5. With this damping factor the beginning of the observations near the arrival time is emphasized in the inversion, and it places more resolution on the model recovery of the deep crust.

As demonstrated in Figure 5, a small shift in timing of $S_{m} S$ relative to direct $S$ can usually improve fits. The flexibility provided by the interference with the two neighboring reflections is also very useful in modeling the $S_{m} S$ triplication. Adjusting the timing in the surface layer multiple can likewise improve fits, although we have downweighted their contributions to concentrate on the deeper structure. As discussed in more detail later, the surface waves are sensitive to the changes in azimuth because of the position of local basins. That is, paths from the northernmost events cross local structures as they approach each station quite differently than the southernmost events (see Figure 1). This forces the solution to take on an average shift (block).

\section{Results}

Preliminary runs revealed a tendency for faster velocities to occur toward the west. This feature has been observed before

[Mori and Helmberger, 1996]. Thus we allowed a separate set of boxes for the section west of the San Andreas, although such a boundary cannot be identified precisely. We also experimented with a set of boxes for the surface layer. Results assuming three surface layer sections are given in Plate 1. Since it is difficult to judge how significant any particular simulation may be, we started by comparing inversion results as a function of the number of events used in the modeling, in particular 7, 19, and 25. The events chosen are indicated in Figure 1 and have been picked to be representative of the population. The results proved quite stable with very rapid

GSC (Event 07) $\Delta=91.9 \mathrm{~km}, \mathrm{~h}=8 \mathrm{~km}$

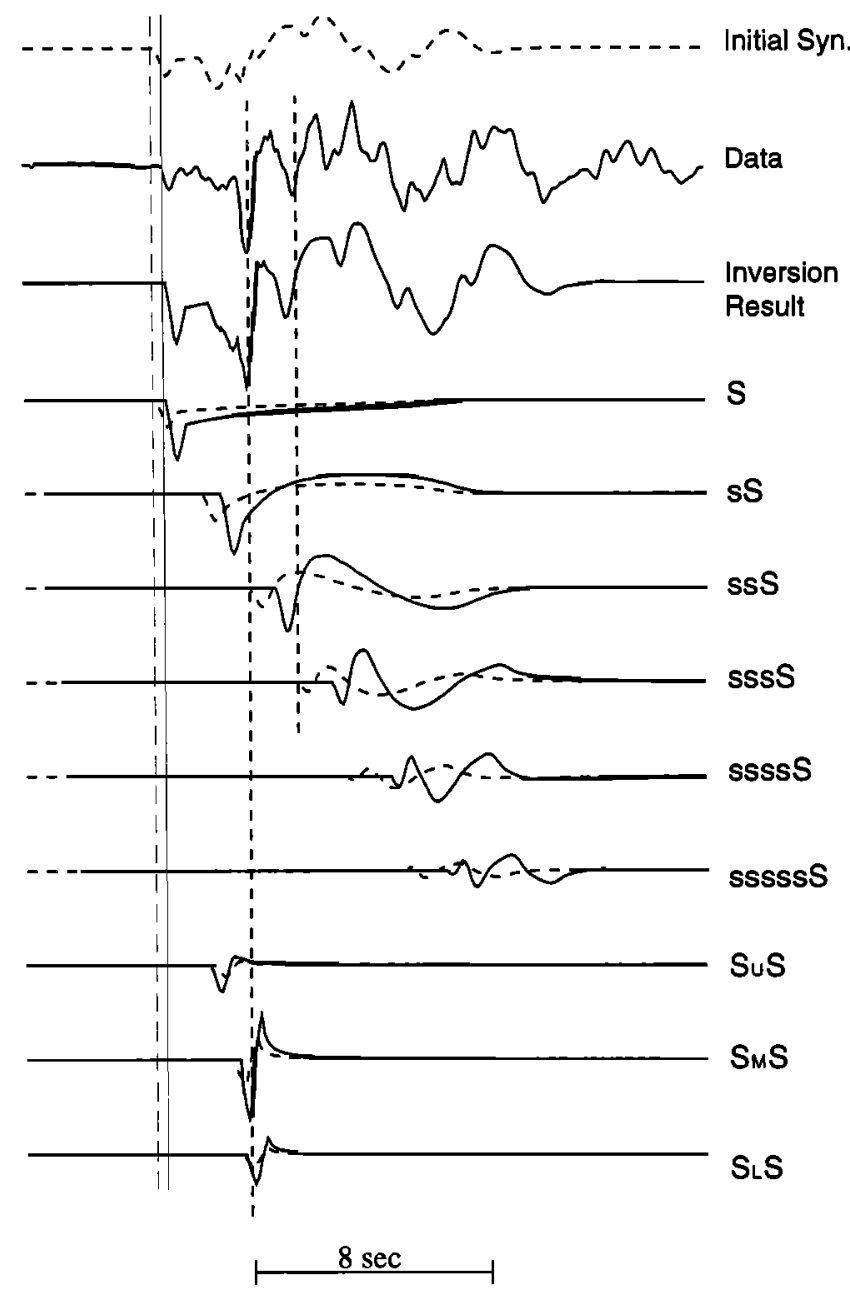

Figure 5. Pseudo-Green's function simulation procedure. The top trace displays the synthetics constructed from 1-D Green's function with appropriate mechanism and moment. Middle trace displays data, and lower trace displays the pseudoGreen's function. An amplification factor has been added to maximize the correlation with the data since the moment estimate comes from the network average and does not necessarily agree with individual observations. The lower set of traces show the shifting of the surface waves (direct plus surface multiples, six responses, and the bottom three include the $S_{m} S$ rays). Note the small shifts back in time to match the data, dotted (original) and solid (shifted). Reference lines have been added to better observe the ray-shifting procedure. 


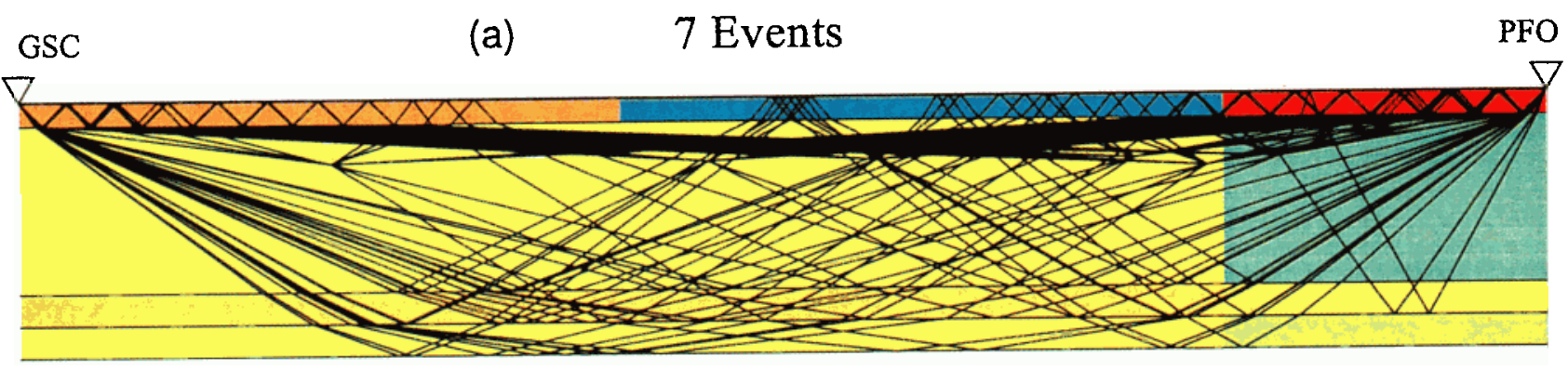

(b)

\section{Events}

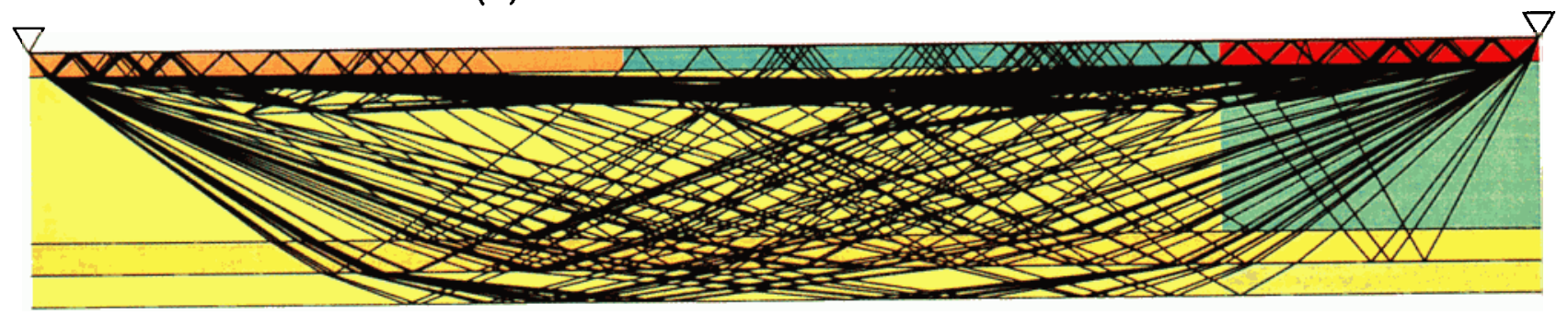

(c) 25 Events
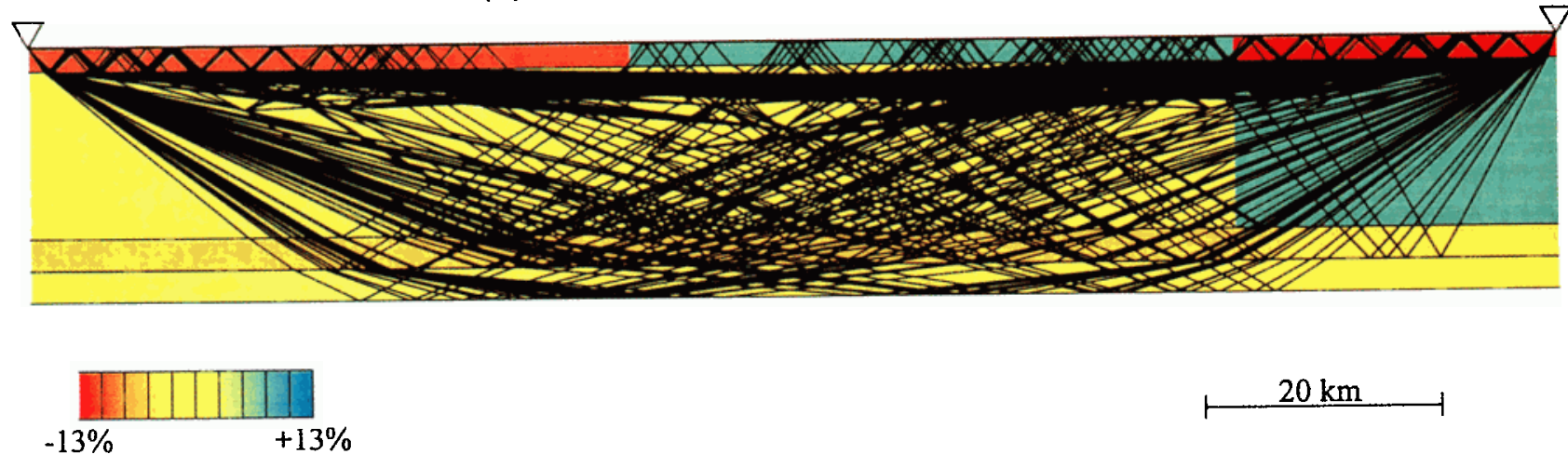

Plate 1. Comparison of results as a function of the number of the events used. (a) Result of inversion using 7 events (white stars in Figure 1); (b) 19 events (black and white stars); and (c) 25 events (all stars). The upper layer is divided into three blocks, while the lower layers have only one division assumed to be at roughly the San Andreas fault boundary. In these inversions, source depth is allowed to move by up to $3 \mathrm{~km}$ except that they are not allowed to cross layer boundaries. The event origin times can vary by up to $1 \mathrm{~s}$. The velocity step sizes are $1 \%$. 


\section{Origin Time}

\section{Source Depth}

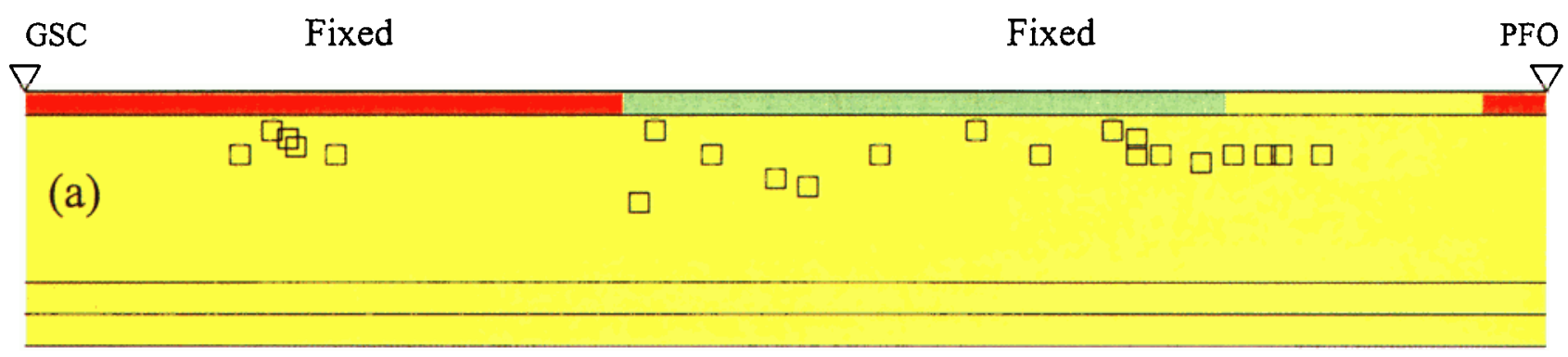

Fixed

Max. $+/-3 \mathrm{~km}$, step $1 \mathrm{~km}$

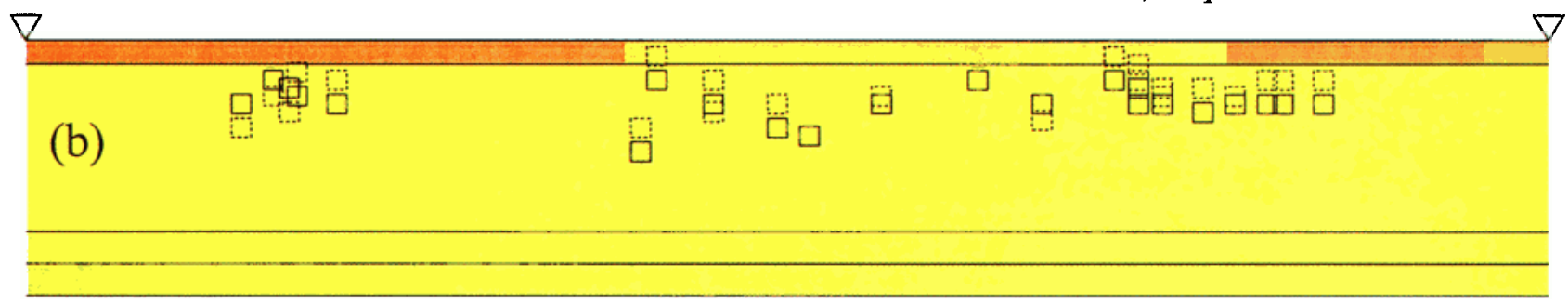

Max. $+/-1 \mathrm{sec}$, step $0.2 \mathrm{sec}$

Fixed

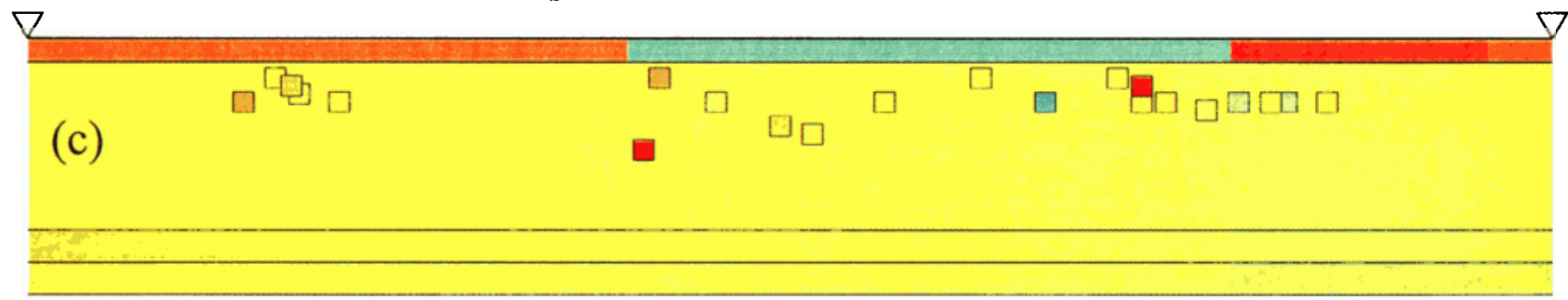

Max. $+/-1 \mathrm{sec}$, step $0.2 \mathrm{sec} \quad$ Max. $+/-3 \mathrm{~km}$, step $1 \mathrm{~km}$

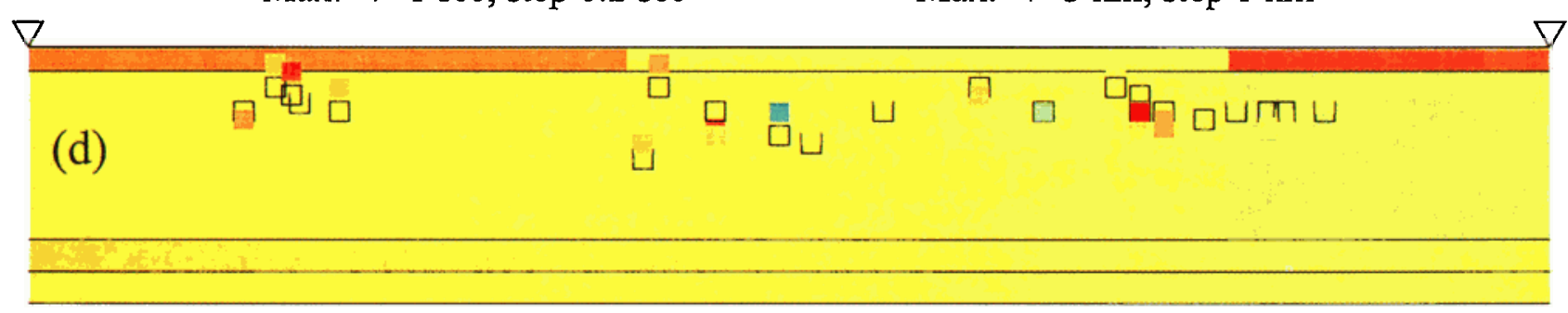
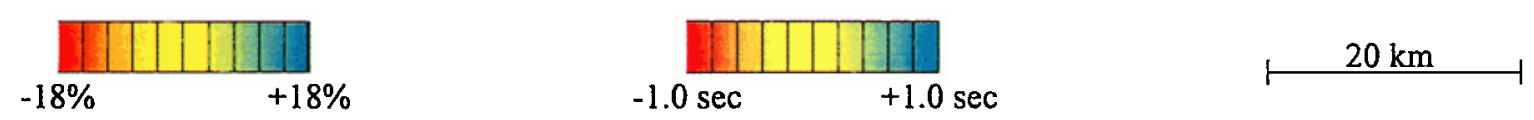

Plate 2. Comparison of results ( 25 events) with various assumptions about source constraints. Origin times have been allowed to vary in steps of $0.2 \mathrm{~s}$ over the range of $\pm 1 \mathrm{~s}$, and the step size in depth variations have been set at $1 \mathrm{~km}$. Velocities are allowed to vary up to $18 \%$ in steps of $1 \%$. The black boxes specify the original depth, while the position of colored boxes indicates the relocated depth. The actual color indicates the origin time delay (negative) or advancement (positive). 


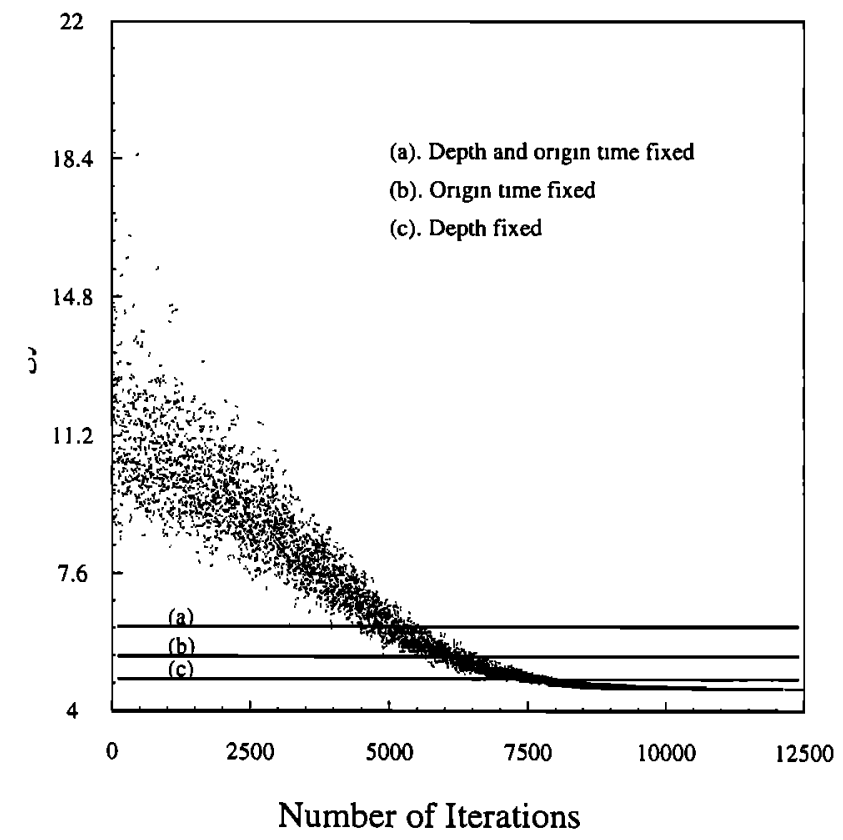

Figure 6. System energy, or the LS error between data and synthetics, as a function of the number of iterations into the inversion, where both the event origin time and the source depth are allowed to vary. The asymptotes for the other three cases shown in Plate 2 are indicated by the lines.

changes in the surface layers ranging over $\pm 13 \%$. The section enclosing the upper Coachella Valley appears particularly slow, which might be expected. Actually, the surface variation in this section is quite compatible with local geology as can be seen by comparing with Figure 1 where the mountainous regions appear relatively fast relative to the basins.

A rather surprising result is the low-velocity zone added at the base of the crust. This feature appears robust and it is caused by a required offset (delay) between the direct arrival and $S_{m} S$. A thicker crust would also increase the delay but moves the critical reflection range beyond $85 \mathrm{~km}$, which violates the data. The thickness used here is $28 \mathrm{~km}$, which is also compatible with the receiver function results of $\mathrm{Zhu}$ and $\mathrm{Ka}$ namori [2000] and Ammon and Zandt [1993]. Our parameterization precludes resolving the true depth of such a zone but only indicates low-velocity occurring below the direct arrival paths. The large velocity contrast across the San Andreas is probably a maximum estimate. Part of it can be reduced by allowing the origin time and depth to vary and introducing a block directly below PFO.

\subsection{Trade-offs and Goodness of Fits}

The results in Plate 2 use all 25 events but also allow some more variables by including an additional block beneath PFO, which can affect absolute velocities. Plate 2a does not allow the origin time or the source depth to change where $V_{\mathrm{s}}$ is allowed to vary in $1 \%$ step sizes. In Plate $2 b$ we allow the source depth to vary in steps of $\pm 1 \mathrm{~km}$ with the origin time fixed. Note that most of the events move upward (dotted boxes), which tends to lengthen the separation between $S$ and $S_{m} S$ by shifting $S$ forward (ahead) and $S_{m} S$ back (behind). This feature eliminates the need for lowering the lower crust velocities. Plate $2 \mathrm{c}$ displays the results for fixed depth but variable origin times. The velocity structure appears quite similar to Plate 2a and the results found in Plate 1 , with a low-velocity layer developing at depth on the GSC section. Plate $2 \mathrm{~d}$ allows both the source depth and origin time to vary. As one would expect, the assumption allowing the most freedom yields the best fits. This can be seen in Figure 6, which indicates the energy error produced by the simulated annealing procedure. The number of parameters increases from top to bottom with Line a containing 10 variables ( 4 velocities in top layer, and 2 each in layers 2,3 , and 4 ). Line b contains 25 more parameters, which is the same as in Line c. Line $d$ contains a total of 60 parameters and yields the best possible fits with the lowest energy asymptote. The other cases have similar plots of points but converging on higher energy levels as displayed in Figure 6. Choosing the most reasonable solution becomes difficult. Our approach is to examine all the waveform comparisons and source constraints to arrive at a reasonable geophysical interpolation. While Plate $2 \mathrm{~d}$ produced some excellent fits, it moved some of the sources into the top layer, which is not appropriate for our original approximations (source must stay in original layer). Moreover, the goodness of fit is not that much better than Plate $2 c$. Plate $2 b$ also violates the source layer criterion. Examining forward calculations for the whole array for these events demonstrates that the source depths are quite well constrained, primarily by the interference of $p_{n}$ and $s p_{n}$ [Jones and Helmberger, 1998]. However, the origin time remains the most uncertain since it can trade off with the velocity model. Thus we prefer the model in Plate $2 c$, where the top layer ranges

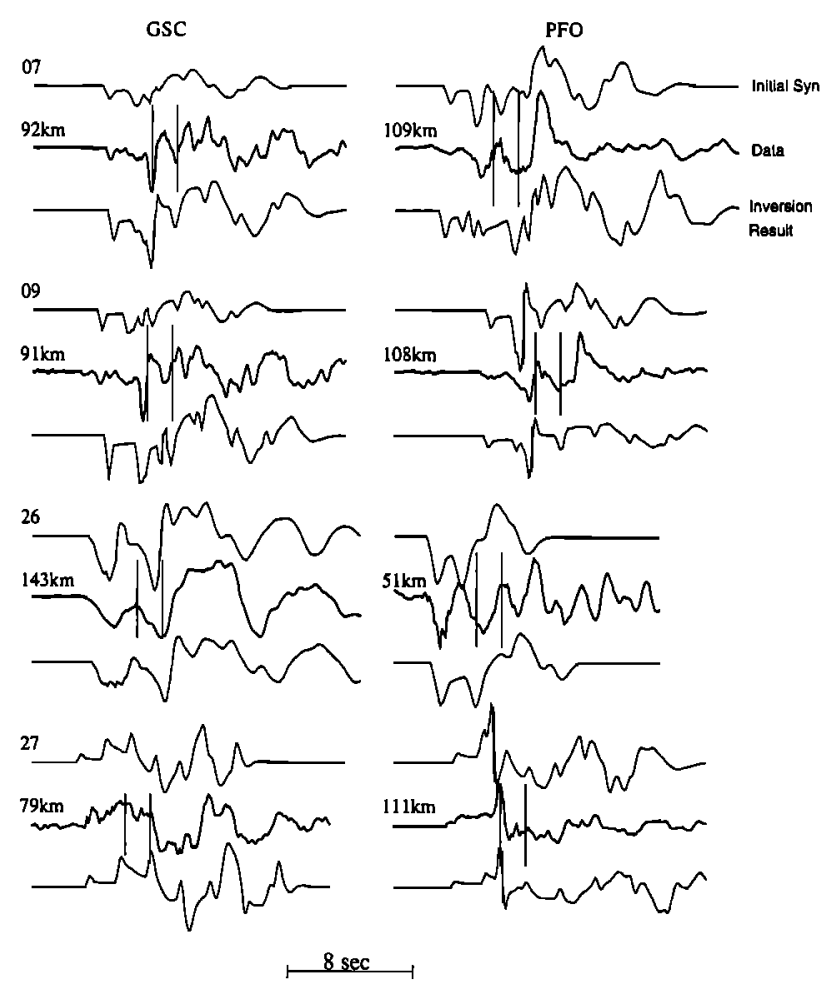

Figure 7. Example comparisons of 1-D synthetics (top trace), with data (middle), and simulated (after shifting) (bottom) for four events $\left(7,9,26\right.$, and 27). The vertical bars indicate the $t_{0}$ and $t_{1}$ time mark for the damping function described in text. Source-receiver distances are shown. 

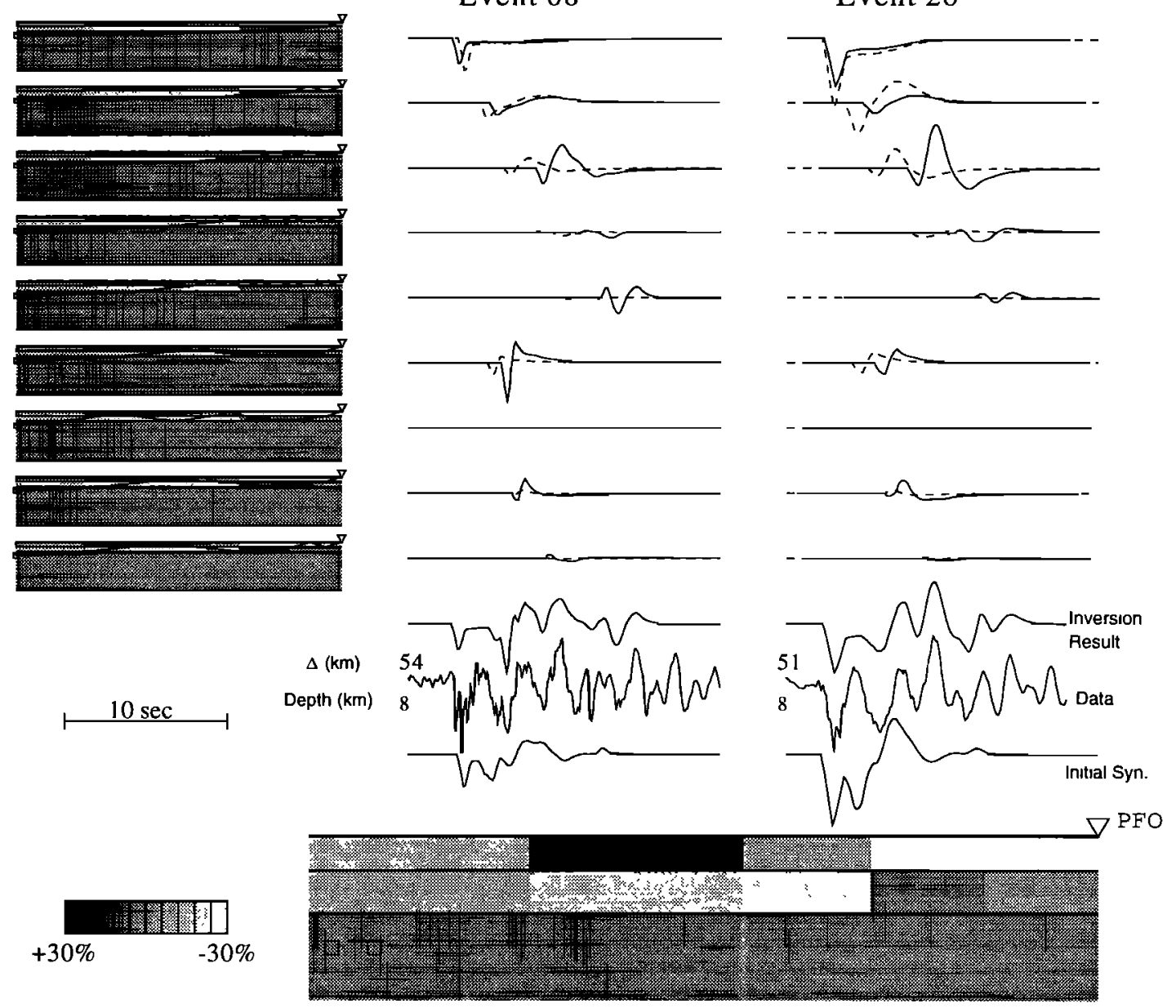

Figure 8. Simulation exercise with PFO data from events 8 and 26, in an attempt to resolve shallow structure near station PFO. Both amplitude and timing are allowed to vary. Top panel displays the amplification and shifting of individual rays, with the ray paths shown to the left. Middle panel compares data (middle trace) with synthetics before (bottom trace) and after (top) the inversion. Bottom panel shows the resulting model. The reference model contains two shallow layers with thicknesses of 2.5 and $3 \mathrm{~km}$ and velocities of 2.6 and $3.45(\mathrm{~km} / \mathrm{sec})$ respectively.

in velocities from $2.26,2.86,2.18$, and 2.24 from left to right. The latter block is probably too low and may be affected by the Coachella Valley as discussed later.

\subsection{Waveform Comparisons}

After experimenting with the full set of 34 events, we eliminated 9 events, mostly because only one station was available. Thus we worked with 50 recordings. A sample of the improvements in waveform matchings obtained by applying these shifting perturbations is displayed in Figure 7 for our preferred model in Plate 2c. Because of the geometry, most events are either near GSC or PFO and thus only one station samples the Moho triplication. These four events display some of the more important constraints where the timing between $S$ and $S_{m} S$ is being fit simultaneously. It also indicates some of the shortcomings of approximating a 3-D crust with such an idealized 2-D model containing only a few layers.

To focus our efforts on resolving the Moho structure, we applied the damping factor $(1 / e)$, starting at the first bar and ending at the second, as discussed earlier. Thus $s S_{m} S$ resolution may have suffered somewhat, in that this particular phase is not fit very well for the top two events in Figure 7 at PFO. However, the strength of $s S_{m} S$ is too weak in the original synthetic response (Figure 2) so that fitting these pulses without amplifying those ray responses probably cannot be achieved. To produce stronger $s S_{m} S$ at these ranges requires moving critical angle to smaller ranges, introducing a stronger lowvelocity zone in the lower event or thinning the crust. A simple experiment was carried out to investigate the role of amplitude variation as a function of azimuth and ray parameter. In this experiment, we applied the time shifts to the ray responses produced by the 25 -event inversion (Plate $2 \mathrm{c}$ ) and only allow the amplitude of the ray responses to vary by a factor of 2 . In this way, we inverted for an amplitude factor for each ray, which is the ratio between the observation and the 1-D ray synthetics. This ratio is presented in Figure 1 as shaded dots, plotted at surface reflection points of individual rays along the ray path. The darkness of the dots is proportional to the amplitude ratio for the corresponding rays. The pattern near the events is indicative of $s S_{m} S$ variations, whereas the pattern near the stations is controlled by the strengths of the surface bounce multiples. Some of the rapid changes in the former are indicative of shallow focusing and defocusing, and some are caused by deeper structure as mentioned above. Variations in the shallow structure are more obvious and correlate with geology. For example, at PFO (Figure 1), paths crossing the Coachello Valley requires amplified multiples, while paths to the north are reduced. One single layer is not very effective in 


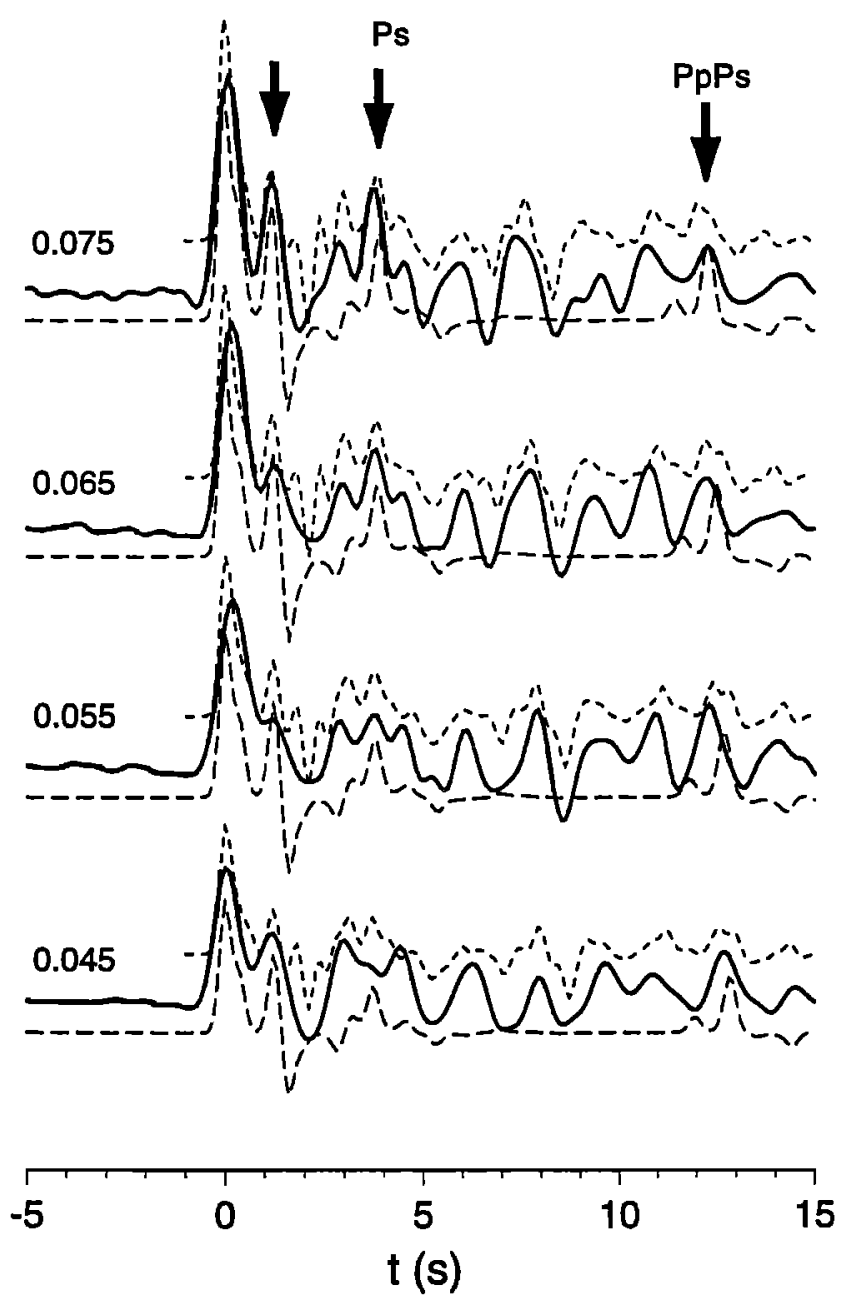

Figure 9. Receiver function comparison of data (thick) versus synthetics (short dashed) over four ray parameters $(\mathrm{sec} / \mathrm{km})$, $(0.075,0.065,0.055,0.045)$. The bottom set of traces (long dashed) allows only a two-layer crust, while the upper set of traces allows 21 layers (see Figure 3). The first arrow indicates a $P$-to- $S$ conversion associated with a shallow interface (probably within the top $4 \mathrm{~km}$ ). $P_{s}$ is probably the Mohoconverted phase and $P_{p} P_{s}$ is the crustal multiple.

modeling these local surface waves as can be seen in Figure 7 (event 26), which is one of the reasons for downweighting their contributions to the waveforms.

We initiated a few runs to test the feasibility of determining local structures with a few of the PFO records including event 26. The results are displayed in Figure 8, where both timing and amplitudes are allowed to vary. Introducing the lowvelocity blocks proved effective in producing the ringing as shown in the data and the increased amplifications in later multiples that would be expected as modeled in 2-D finite difference experiments [i.e., Dreger and Helmberger, 1990]. However, the model variations are extreme, and again the need to regenerate ray responses with the updated models is evident.

\section{Discussion}

The above attempts at inverting whole regional recordings have probably revealed more about the difficulty of the problem than about the true structure. In contrast, many record sec- tions from conventional refraction profiling (explosions) look quite simple and have been modeled convincingly [i.e., Fuis et al., 1982]. Thus, why should modeling these earthquake data be so difficult? There are many reasons: $S$ velocity structure is probably more complex than $P$ velocity structure with its stronger dependence on temperature; earthquakes have complex source characteristics, and we do not really know where they occurred and when. Moreover, the various sources excite the waveguide differently, producing more 3-D effects than presently appreciated (at least by US authors). To proceed, we can use the results of other, more well-developed techniques to limit the parameter space or invert in conjunction. One such useful approach for recovering crustal structure is receiver function analysis by inverting teleseismic $P$ wave signatures.

\subsection{Crustal Structure From Receiver Functions}

Following this approach, one assumes that the $P$ wave recorded on the vertical component can be considered to be effectively the source history and remove it from the radial by deconvolution [i.e., Ammon et al., 1990]. Laterally scattered phases can be reduced by further stacking over azimuth at constant ray parameter. A further refinement in receiver function

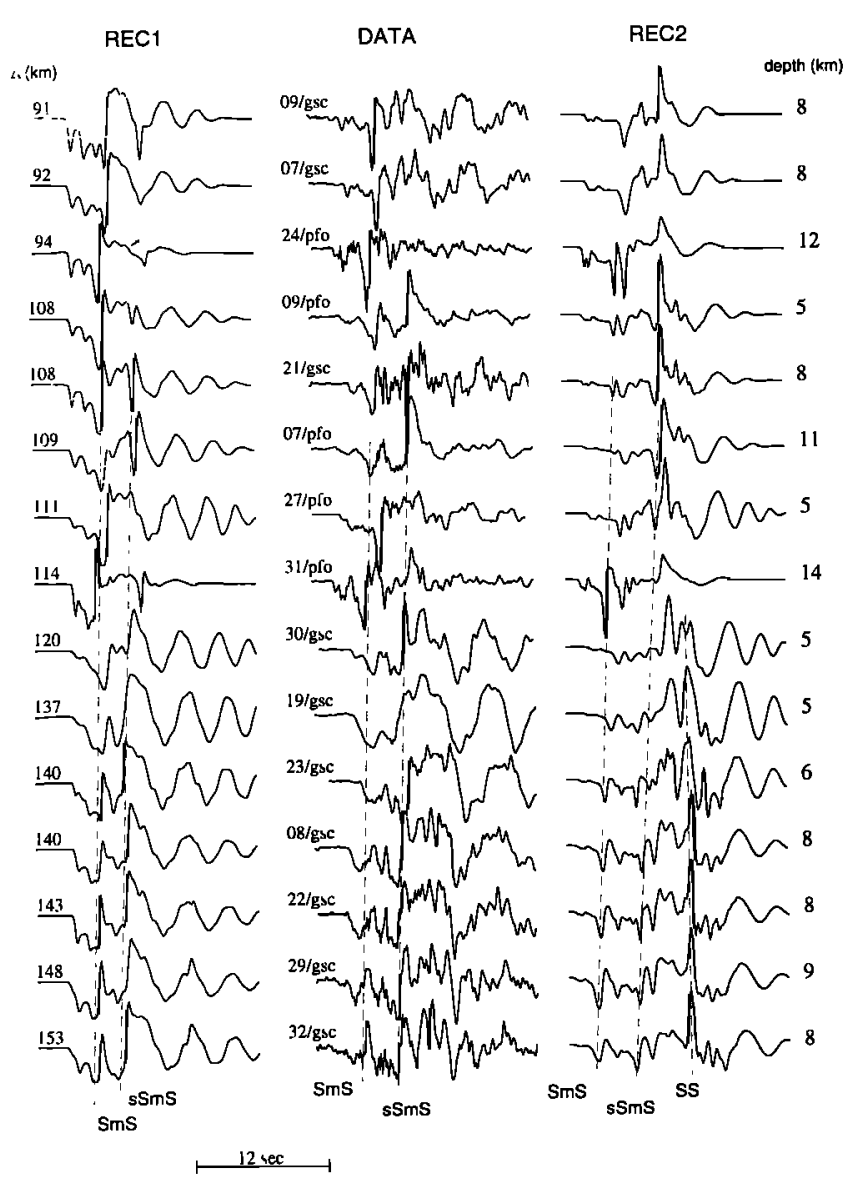

Figure 10. Comparison of (middle) data and synthetics for (left) model REC1 (2-layer model) and (right) REC2 (21-layer model). Synthetics are computed with the reflectivity method. The record sections are plotted with a reduced velocity of 3.6 $\mathrm{km} / \mathrm{s}$ as before. Source-receiver distances are shown on the left, and event depths are shown on the right. Event numbers (Table 1) and station names are given in the middle column containing the waveform data. 

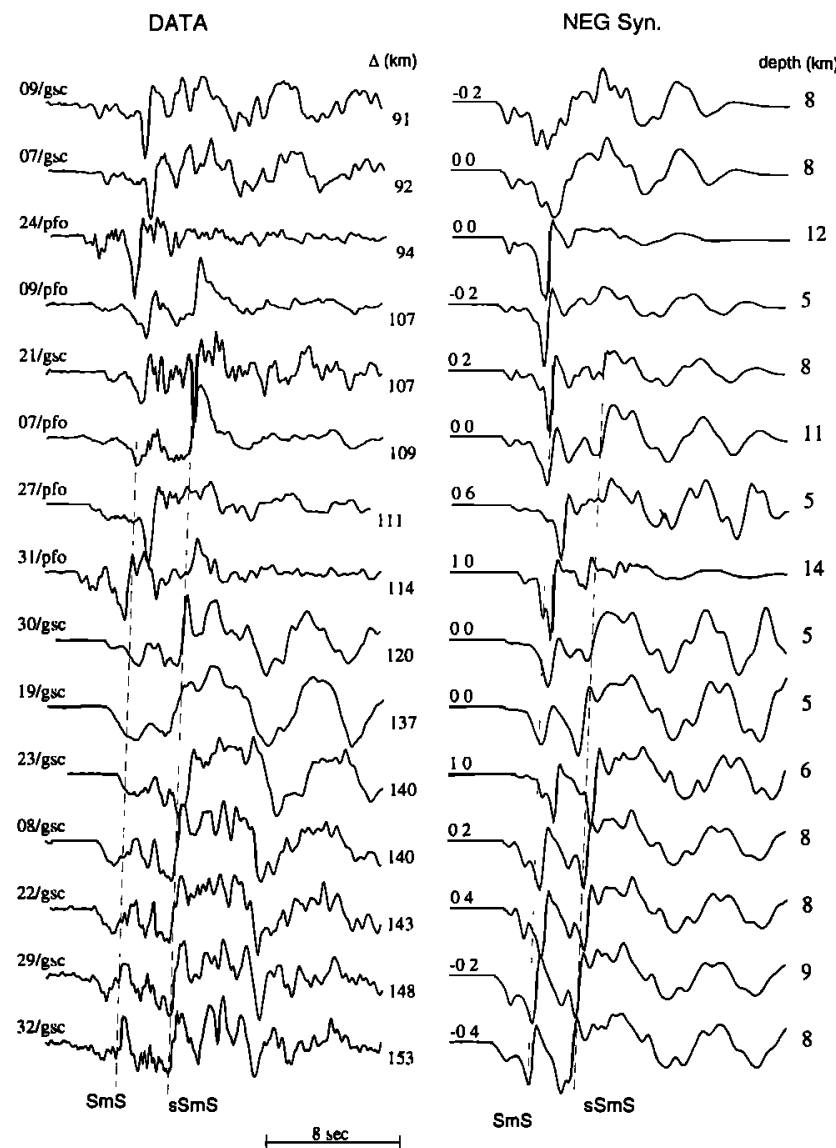

Figure 11. Synthetics (NG, Figure 3) against observations with timing shifts above synthetics (indicated in seconds) derived by Jones and Helmberger [1998]. Included are the ranges in $\mathrm{km}$ (91 to 153 ). The event numbers and station names are given on the left, indexed to Table 1.

analysis introduced by $Z h u$ and Kanamori [2000] treats the trade-off in Moho depth estimation caused by variation in the $V_{p} / V_{s}$ ratio. They stack at arrival times for $P_{p} P_{s}$ and $P_{s} P_{s}+$ $P_{p} S_{s}$ based on various assumptions of crustal thickness $H$ and $V_{p} / V_{s}$ ratios. Numerical experiments produced convincing results displaying consistency at neighboring stations. However, attempts at retrieving information about layering become more problematic, as discussed below. Figure 9 shows the stacked receiver functions for station GSC from 290 teleseismic events. We divided these events into four groups according to their incidence angles (as measured by the ray parameter $p$ ) and stack all receiver functions in each group. This reduces the effect of lateral structural variation. The prominent signals in the receiver functions in Figure 9 are a $P$-to- $S$ conversion from a shallow velocity interface, $\sim 1 \mathrm{~s}$ after the direct $P$, and the Moho $P_{s}$ phase at $\sim 4 \mathrm{~s}$. The Moho multiple conversion phase $P_{p} P_{s}$ occurs at $\sim 12 \mathrm{~s}$ and tends to be difficult to identify even on the stacked traces. The four-averaged receiver functions were inverted simultaneously for a $1-D$ velocity model near GSC. We first limited the number of layers in the crust to 2 and found an "optimal" simple model to satisfy the major features on the receiver functions, as mentioned above. Then we relaxed the limitation and divided the model into many layers with thicknesses of 1 to $2 \mathrm{~km}$ (total of 21 layers). Both models are shown in Figure 3. The 21-layer model produces a better fit to the data. However, examining the waveform fits shows that part of the complexity in the model is the result of the inversion trying to fit the shallow $P_{s \text {. }}$ This phase displays some rapid variations with ray parameters and azimuths that are most likely caused by lateral structural variation. Therefore it is possible that some nonplanar structures are mapped into the complexity of the 1-D model.

\subsection{Waveform Comparisons}

These models can be tested against the regional data with synthetic predictions given in Figure 10. Although some comparisons show promise, most do not fit as well as those in Figure 2. Overall, the 2-layer model fits the regional observations better than the 21-layer model (error estimate). The 2layer model fits the separation between the first arrival $(S)$ and $\left(S_{m} S\right)$ quite well at some stations, i.e., event $24 / \mathrm{PFO}$, except the first arrival is too strong in the synthetic. Appealing features from the 21-layer model are the strengths of $s S_{m} S$ at the nearest ranges (90-114 km) and the SSS development (about $12 \mathrm{~s}$ back) at the larger ranges (120 to $153 \mathrm{~km})$. Also, the weak beginning of direct $S$ agrees with the observations quite well. These two models appear to bracket the observations, and designing a new model capturing the best features from these test models could be pursued, or using the receiver data along with the regional data directly in a joint inversion. Alternately, we could use these results to fix the Moho depth [ $\mathrm{Zhu}$ and $\mathrm{Ka}$ namori, 2000]. Both GSC and PFO yield a depth of $29 \mathrm{~km}$, and assuming this value, we can generate a new model containing a low-velocity zone in the lower crust (Figure 3 (NEG)) compatible with our modeling exercise. Synthetic productions are given in Figure 11. These fits are actually quite good and explain nicely the weak $S$ onset common in the data. However, the difficulty with explaining the strong $S_{m} S$ at $09 / \mathrm{GSC}$ and the strength of $s S_{m} S$ at 09/PFO remains a problem. These features could probably be explained by allowing some windows in the fastest crustal layers. That is, the $S_{m} S$ phase could reach critical angle at a shorter distance if a section of the fastest layer in the upper crust (lid) is missing in some segment. Such features appear to be observed in some of the $P$ wave tomographic models along this profile [Hauksson, 2000].

Thus, to obtain better modeling results, we need to regenerate these ray responses with the 2-D perturbations to move our synthetics closer to data. This approach appears possible using the new analytical method designed for this purpose, $\mathrm{Ni}$ et al. [2000] and will be pursued in future efforts.

In summary, evidence for strong $S_{m} S$ and $s S_{m} S$ arrivals relative to weak $S\left(\Delta_{S M S}<95 \mathrm{~km}\right.$ and $\left.\Delta s S_{m} S<110 \mathrm{~km}\right)$ argues for slow velocities in the lower crust beneath the western Mojave block (Landers). This feature seems to correlate with the relative shallow seismicity and recent estimates of viscoelastic behavior in this particular region (Landers) as reported by Deng et al. [1998]. Thus a more complete inversion of local seismic waveforms may help us understand the lower crust and the role it plays in tectonic processes.

Acknowledgment. We would like to thank reviewers Rachel Abercrombie, George Zandt, and Brian Savage. This study was supported by the USGS (award 99HQGR0038) and by DTRA (grant DSWA01-98-10010). Contribution 8698 of the Division of Geological and Planetary Sciences, California Institute of Technology.

\section{References}

Ammon, C. J., and G. Zandt, Receiver structure beneath the southern Mojave block, California, Bull. Seismol. Soc. Am., 83, 737-755, 1993. Ammon, C. J., G. E. Randall, and G. Zandt, On the nonuniqueness of re- 
ceiver function inversions, J. Geophys. Res., 95, 15,303-15,318, 1990.

Backus, G. E. and J. E. Gilbert, Numerical application of a formalism for geophysical inverse problems, Geophys. J. R. Astron. Soc., 13, 247$276,1967$.

Chapman, C. H., and J. A. Orcutt, Inversion of seismic refraction data (abstract), Eos Trans. $A G U, 6 I, 304,1980$

Deng, J., M. Gurnis, H. Kanamori, E. Hauksson, Viscoelastic flow in the lower crust after the 1992 Landers, California, earthquake, Science, 282, 1689-1692, 1998.

Dreger, D., and D. V. Helmberger, Broadband modeling of local earthquakes, Bull. Seismol. Soc. Am., 80, 1162-1179, 1990.

Fuis, G. S., W. D. Mooney, J. H. Healey, G. A. McMechan, and W. J. Lutter, Crustal structure of the Imperial Valley Region, U.S.Geol Surv. Open File Rep., I254, 25-49, 1982.

Hauksson, E., Crustal structure and seismicity distribution adjacent to the Pacific and North America plate boundary in southem California, $J$. Geophys. Res., 105, 13,875-13,903, 2000.

Hauksson, E., L. M. Jones, K. Hutton, and D. E. Phillips, The 1992 Landers earthquake sequence: Seismological observations, $J$. Geophys. Res., 98, 19,835-19,858, 1993.

Helmberger, D. V., and G. R. Engen, Modelıng the long-period body waves from shallow earthquakes at regional ranges, Bull. Sersmol. Soc. Am., 70, 1699-1714, 1980

Helmberger, D. V., Theory and application of synthetic seismograms, in Proceedings of the International School of Physics "Enrico Fermi" Course LXXXV, Earthquakes: Observations, Theory and Interpretation, H. Kanamori and E. Boshi (Editors), North-Holland, Amsterdam, 1983.

Jones, L. E., and D. V. Helmberger, Earthquake source parameters and fault kinematics in the eastern California Shear Zone, Bull. Seismol. Soc. Am., 88, 1337-1352, 1998.

Mellman, G. R., A method of body-wave waveform inversion for the determination of Earth structure, Geophys. J. R. Astron. Soc., 62 481-504, 1980.
Mori, J., and D. V. Helmberger, Large-amplitude Moho reflections $(S m S)$ from Landers aftershocks, southern California, Bull. Seismol. Soc. Am., 86, 1845-1852, 1996.

$\mathrm{Ni}$, Sidao, X. Ding, and D. V. Helmberger, Constructing Synthetics from Deep Earth Tomographic Models, Geophys. J. Int., 140, 71-82, 2000.

Sen, M. K., and P. L. Stoffa, Nonlinear one-dimensional seismic waveform inversion using simulated annealing, Geophysics, 56, 1624$1638,1991$.

Song, X. J., and D. V. Helmberger, Source estimation of finite faults from broadband regional networks, Bull. Seismol. Soc. Am., 86, 797 $804,1996$.

Song, X. J., and D. V, Helmberger, Pseudo Green's Functions and Waveform Tomography, Bull. Seismol. Soc. Am., 88, 304-312, 1998.

Zhao, L.-S., and C. Frohlich, Teleseismic body-waveforms and receiver structures beneath seismic stations, Geophys. J. Int., 124, 525-549, 1996.

Zhao, L.-S., and D. V. Helmberger, Source Estimation from Broadband Regional Seismograms, Bull. Seismol. Soc. Am., 84, 91-104, 1994.

Zhu, L., and D. V. Helmberger, Advancement in source estimation techniques using broadband regional seismograms, Bull. Seismol. Soc. Am., 86, 1634-1641, 1996.

Zhu, L., and H. Kanamori, Moho depth variation in southern California from teleseismic receiver functions, $J$. Geophys. Res., 105, 29692980, 2000.

D. V. Hel mberger, X. J. Song, and L. Zhu, Seismological Laboratory 252-21, California Institute of Technology, Pasadena, CA 91125. (helm@gps.caltech.edu)

(Received July 21, 1999; revised May 18, 2000; accepted June 26, 2000.) 